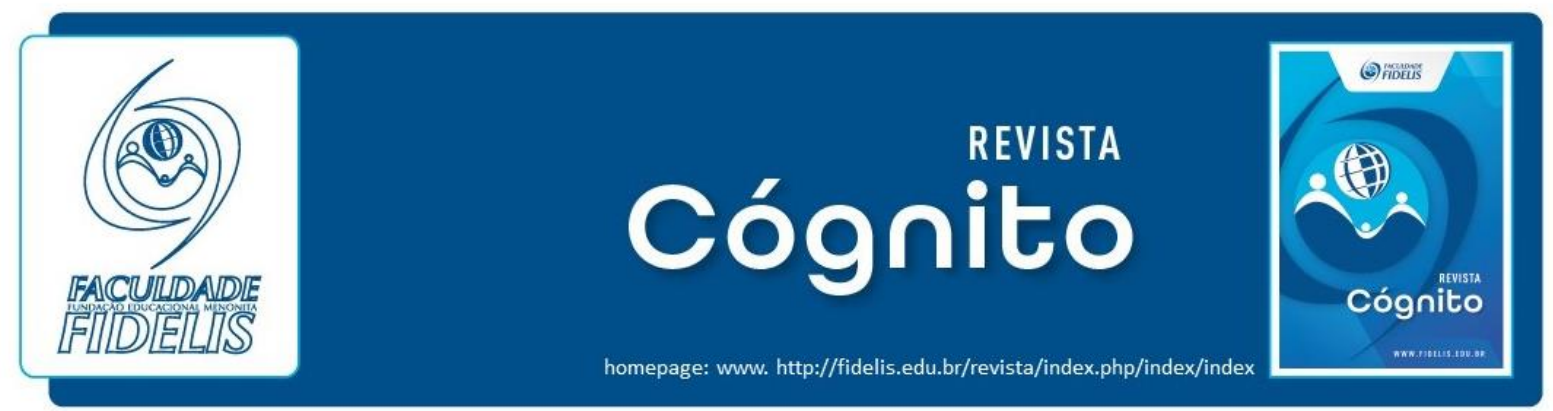

\title{
O SEXO COMEÇA NA IGREJA
}

SEX BEGINS IN THE CHURCH

Uma Perspectiva Pastoral Sobre a Educação Sexual do Cristão

\author{
Fridbert August ${ }^{1}$ \\ André Felipe Klassen ${ }^{2}$
}

\section{RESUMO:}

Este texto trata da necessidade de a Igreja Contemporânea abordar, de forma direta e intencional, a questão do sexo e da sexualidade de seus seguidores. O tema é de extrema relevância no cotidiano de homens e mulheres, a ponto de ser explorado de forma desproporcional por vários segmentos da sociedade. A Igreja, por outro lado, tem como seu manual de conduta a Palavra de Deus, que não é omissa nesse tema, mas tem sido covarde e ausente quando deveria usar esse manual para ensinar seus seguidores.

PALAVRAS-CHAVE: Sexo. Sexualidade. Bíblia. Igreja.

\section{ABSTRACT:}

This essay deals with the urgent need of the Contemporary Church to address, in a very direct and intentional way, the matter of sex and sexuality of its followers. The theme has extreme relevance in both men and women's life, to the extent of being exploited with disproportional weight in several segments of society. The Church, on the other hand, having the Bible as its conduct manual - which is in no way silent about the matter - has not been courageous enough when it comes to using Scriptures to teach their followers about sex and sexuality.

KEYWORDS: Sex. Sexuality. Bible. Church.

\footnotetext{
1 Bacharel em Administração de Empresas pela UFPr; MDiv: Pastoral Care and Counseling pela AMBS (IN, EUA), Pós-graduação em Ministério Pastoral pela Faculdade Fidelis. Pastor na Igreja Evangélica Menonita Água Verde, Curitiba. Docente do curso de Bacharelado em Teologia da Faculdade Fidelis, fridbert@iemav.org.br. ${ }^{2}$ Bacharel em História pela UFPR. Bacharel e Mestre em Teologia pela FABAPAR. Pastor na Igreja Família Cristã Menonita, em Curitiba. Docente do curso de Bacharelado em Teologia da Faculdade Fidelis, andre.klassen@erasto.com.br
} 


\section{INTRODUÇÃO}

A Igreja tem lutado com questões relacionadas a sexo e sexualidade por séculos. Mesmo antes de ser chamado de 'Igreja', o povo de Deus tem tido problemas com várias questões relacionadas a esta matéria. Desde os filhos de Noé terem visto o pai nu até o adultério de Davi com Bate-Seba, comportamentos abusivos dos maiores heróis do Antigo Testamento denotam o quão difícil é abster-se de erros a esse respeito e como as consequências disto podem ser devastadoras. Há leis em vigor, estabelecidas por Deus, e muitas vezes ampliadas ou estendidas pelo homem, que objetivam alcançar o mínimo de paz nesse quesito. Mas, para alguns, estas podem ser consideradas controversas, injustas e inadequadas para, por si só, assegurarem paz e justiça entre o povo de Deus. Frequentemente leis não foram bem sucedidas na orientação para um comportamento saudável do povo de Deus, mesmo quando seguidas à risca. Tome-se, por exemplo, o quarto mandamento, obedecido de maneira radical pelas autoridades contemporâneas do ministério de Jesus, mas que foi um dos mais frequentes motivos de discórdia entre líderes e o Messias.

Como reação a séculos de lutas na área da sexualidade, o diálogo sobre sexo foi evitado em muitos ambientes da Igreja. Como em um relacionamento entre duas pessoas que são incapazes de se comunicar de uma forma saudável, o silêncio parece ser a opção mais frequente. A Igreja frequentemente tem silenciado sobre o tema, embora os dilemas relacionados a ele sejam mais presentes do que nunca na vida de seus membros. Esses, em contrapartida, têm também optado pelo silêncio, não apresentando suas lutas e dilemas à comunidade e sua liderança.

A frequência e a intensidade com que o cristão é confrontado com o tema do sexo fora da igreja são simplesmente devastadoras, quando comparadas com a menção ao tema dentro dela. Winner afirma que uma pessoa estará exposta a cerca de cem mil referências a sexo ao longo de sua vida apenas assistindo à televisão (WINNER, 2005, p. 63). Duarte, de maneira bem mais descontraída, afirma: “Olhe à sua volta por um instante e você só verá sexo, explícito e implícito. Ele é usado para vender carro, vinho, aparelho de TV, meia, celular e até sandália Havaiana” (DUARTE, 2014, p. 7). Em contrapartida, o cristão ainda enfrenta dilemas semelhantes ao de Agostinho que, no quarto século de existência da Igreja, afirmava que o desejo sexual era pecaminoso por si só. Em uma de suas orações, escritas em "Confissões", evidencia seu desespero: "Dá-me castidade e continência, mas não agora” (AGOSTINHO, 2011, p. 17). 
O uso da palavra 'diálogo' é intencional, uma vez que denota uma via de mão dupla. Não é só a Igreja que deve formar a prática e a identidade sexual de seus membros. Ao mesmo tempo, a sexualidade dos membros é formativa para a Igreja. Visto de maneira simplista, vida da Igreja não é mais do que a soma da vida de seus membros e famílias. Portanto, seria incompleto observar somente a orientação da Igreja sobre este ou qualquer tema, sem que se considere qual a prática de seus integrantes.

Quais são as razões para esse silêncio e quais têm sido os danos desta prática? Existe um caminho saudável para que uma congregação, em no conturbado contexto social já mencionado, que vive já saturado e sobrecarregado de sexo, seja relevante e formativa quando se trata da sexualidade humana? Quais são alguns passos práticos que se poderiam considerar quando se ministra em um ambiente congregacional, seja do púlpito ou em conversas individuais (exemplos de duas das abordagens do cuidado pastoral)?

O presente texto argumentará que é responsabilidade da Igreja levantar sua voz e falar sobre sexo. Deve haver diálogo, e a iniciativa cabe à liderança da Igreja. Seus líderes são chamados a abordar o tema, a orientar sua congregação, a apontar para os conceitos bíblicos e, por fim, fomentar a criação de um contexto favorável para a criação de uma sexualidade saudável entre seus seguidores. Além disso, os pecados relacionados com o sexo deveriam ser tratados com muito mais seriedade do que a maioria das práticas observadas tem demonstrado. Há demais tragédias pessoais mantidas em silêncio, muitas vezes de forma intencional por parte da liderança, em função de causas muito menos importantes do que a cura das vítimas e a restauração dos relacionamentos. Finalmente, o texto argumentará que a Bíblia, mesmo tendo sido escrita em um contexto significativamente diferente do atual, ainda é o parâmetro que orienta passos neste sentido.

O presente texto foi desenvolvido a partir da pesquisa bibliográfica, que apontou para certa escassez de material acadêmico brasileiro sobre este tema. Há livros escritos sobre a sexualidade no Brasil, porém em quantidade proporcionalmente inferior à importância do tema. E, aqueles materiais disponíveis raramente abordam para o papel da Igreja no processo formativo de seus membros. Têm seu foco no comportamento individual (ou de casal), e pouco se aborda o papel da Igreja neste processo. Também não foi possível encontrar uma discussão acadêmica sobre a questão ética da sexualidade escrita no contexto brasileiro. O uso de autores como Hollinger, Cahill e Gushee, todos norte-americanos, indiretamente aponta para o silêncio ou até para a omissão deste assunto no contexto brasileiro. 


\section{DEFINIÇÃO DE SEXO E SEXUALIDADE}

As palavras 'sexo' e 'sexualidade' foram utilizadas de forma aleatória até aqui, assim como tem sido observado em algumas literaturas utilizadas neste artigo. No entanto, faz-se necessário uma distinção clara entre os dois termos, que serão tomados de forma distinta na continuação deste texto. O dicionário Michaelis Online define a palavra 'sexo' como sendo "[O] instinto genésico, atração sexual ou sua manifestação na vida e na conduta" (http://michaelis.uol.com.br, s.d.). Esta definição, já excluídas as demais que estão relacionadas a gênero e expressões gramaticais, de pouco ajuda na definição do termo, e por outro lado evidencia a falta da clareza necessária para o correto entendimento da questão. Outro dicionário, o Aurélio Online, apresenta uma definição mais concisa e clara: "Relação sexual" (https://dicionariodoaurelio.com, s.d.).

Hollinger define sexo como "o ato da intimidade física" (HOLLINGER, 2008, p. 15) 3 . A definição de Hollinger é breve e bastante incompleta, uma vez que poderia, teoricamente, ser usada para certo contato entre uma mãe e seu filho sem qualquer conotação sexual. A palavra sexo será empregada neste artigo como referência ao intercurso sexual. Será referência a qualquer tipo de contato íntimo, envolvendo duas pessoas e o contato físico da genitália de pelo menos uma delas - embora o sexo não esteja limitado a estas condições.

Sexualidade, por outro lado, é a qualidade intrínseca de cada ser humano, não sendo limitada a idade, estado civil, envolvimento ou não do indivíduo em um relacionamento onde o sexo é praticado, ou mesmo se o indivíduo já praticou sexo ou não. A definição de sexualidade de Hollinger é: "Nossa masculinidade e feminilidade como seres humanos" (HOLLINGER, 2008, p. 16). Mais uma vez, a definição é limitada e até certo ponto equivocada, uma vez que este é sim um conceito de gênero e não oferece uma opção para pessoas transexuais ou reconhece a sexualidade implícita em um bebê.

Em outras palavras, a sexualidade não pode ser resumida à masculinidade ou feminilidade, mas está presente em todo ser humano. A compreensão equivocada de que a sexualidade não está presente em pessoas sexualmente não ativas, como por exemplo, em crianças ou pessoas sem parceiros sexuais, muito provavelmente é a base para alguns dos erros que a Igreja tem incorrido neste campo. Recém-nascidos, desde seu primeiro fôlego são seres sexuais e sujeitos a serem influenciados positiva ou negativamente em sua sexualidade (SILVA,

\footnotetext{
${ }^{3}$ Tradução nossa, nesta e demais citações desta fonte.
} 
2007, p. 11 $)^{4}$. A sexualidade está presente em todas as fases da vida humana. Indivíduos abstinentes (não envolvidos em atividade sexual) têm necessidades em relação à sua sexualidade, que vão além do mundo físico. Estas também deveriam ser reconhecidas e tratadas.

\section{DELIMITANDO O ARTIGO}

Para definir os limites de um tema assim vasto, algumas linhas gerais, além das definições apresentadas acima, serão úteis. Como já mencionado na introdução, sexo e sexualidade serão descritas no contexto de pessoas ligadas a uma congregação local. Seguindo uma definição anabatista, essa se refere a "um grupo de pessoas que se reúnem em nome de Deus" (www.aimb.org.br/nossa-fe). Uma vez que a Igreja é formada pelas pessoas reunidas, e exatamente pelo fato de se reunirem, isso inclui todas as áreas da vida da pessoa, incluindo sua sexualidade.

Outra característica deste artigo é que ele fará referência ao sexo como um ato entre duas pessoas de sexos opostos com algum nível de comprometimento mútuo, a não ser quando explicitamente informado de maneira diferente. Não é assunto deste ensaio, portanto, a relação homossexual, o adultério, o sexo entre mais de duas pessoas, etc. Estas práticas estão sob a suposição de práticas não saudáveis, igualmente seguindo a Confissão de Fé Menonita citada acima. Não é o caso que, excluindo estas práticas do âmbito de aplicação do ensaio, signifique também a exclusão dos mesmos dos diálogos entre a Igreja e seus seguidores. A questão aqui é apenas de definição dos limites do texto. Ainda assim, as propostas resultantes podem ser usadas como caminho para a discussão desses temas.

\section{A SEXUALIDADE NA VIDA DO CRISTÃO}

Não poucos tentaram, com sucesso limitado em sua maioria, estabelecer uma argumentação favorável à castidade até o casamento, usando exclusivamente o tex to bíblico, sem interpretações e adaptações. Como já mencionado, o contexto cultural no qual foram estabelecidas estas orientações é significativamente diferente do vivido pela sociedade

\footnotetext{
${ }^{4}$ A psicóloga Marica Cecília Pereira da Silva, em seu livro "Sexualidade começa na infância, afirma que "O fato é que sexualidade não é um tema importante apenas para jovens e adultos(...). Crianças... Também têm sexualidade em suas vidas".

${ }^{5}$ Confissão de Fé da Associação das Igrejas Menonitas do Brasil, artigo 9: "Cremos que a Igreja é a comunhão daqueles que, pela fé recebem a salvação que Deus oferece em Jesus Cristo. É a nova comunidade de discípulos enviados ao mundo para proclamar o reino de Deus e a fazer conhecido o antegozo da esperança gloriosa da Igreja, um povo estabelecido e sustentado pelo Espírito Santo. At. 2.37-47. Disponível em http://www.aimb.org.br/nossa-fe/ Acesso em 22/08/2016.
} 
contemporânea ocidental. Isso de maneira alguma desautoriza a Palavra de Deus em suas instruções e leis. Porém, há que se observar aspectos relevantes ao processo de casamento que diferem significativamente entre o contexto bíblico e o atual, por exemplo: o processo de escolha do cônjuge, o tempo de espera até o casamento, a idade culturalmente aceita para se casar, e até mesmo as instituições envolvidas na cerimônia. São elementos de grande importância no processo do casamento, e por consequência da sexualidade, visto que diferem grandemente da realidade contemporânea. Duarte afirma: "Sexo é coisa de Deus! A Palavra do Senhor, ao contrário do que muita gente pensa, fala, sim, de sexo. E manda fazer direitinho! Ô coisa boa, não é?” (DUARTE, 2014, p. 8). A informalidade e leveza da afirmação devem servir também de inspiração para que o assunto seja tratado de maneira clara e simples.

Mas a distância cultural e social separa o leitor contemporâneo do autor do texto bíblico em todos os aspectos, e não somente nas questões ligadas à sexualidade. Além disso, as instruções do texto não são tão explícitas quanto os mandamentos instituídos pela Igreja: 'Não praticarás sexo antes do casamento!'. Esta afirmação, ou alguma equivalente, não é encontrada em nenhuma das leis do Antigo Testamento, ou mesmo nos ensinamentos de Jesus e seus discípulos no Novo. A pergunta aqui é: na perspectiva cristã, o que é ético quando se trata do sexo? O texto bíblico proíbe e condena claramente o adultério, estupro, incesto e bestialidade ${ }^{6}$, práticas estas que também são condenadas pela grande parte da sociedade, incluindo leis civis de diversas culturas. Mas este não é o caso quando se trata de sexo pré-conjugal.

Várias leis do Antigo Testamento são limitadas em seu alcance e, em muitos casos consideradas injustas, principalmente em relação às mulheres. Em Deuteronômio 22, por exemplo, a falta de prova da virgindade da mulher com base apenas na palavra do homem seria razão para apedrejá-la até a morte. Neste ponto o Antigo Testamento não aborda a castidade ou virgindade do homem, muito menos dá à mulher o direito de se defender ou contra argumentar. No mesmo contexto está definido que um estuprador (homem) deveria pagar uma multa ao pai da vítima (mulher). Observe-se, por exemplo, o estupro de Tamar pelo seu irmão Absalão, relatado em 2 Samuel 13. Neste evento, a ira de Davi, pai de ambos, que se acendeu ao ouvir sobre o violento incesto, não tem qualquer consequência punitiva ao agressor ou restauradora à vítima.

Mas onde estariam então, orientações bíblicas referentes ao sexo? A narrativa bíblica começa com a Criação (Gn 1-2), onde homem e mulher são criados à imagem de Deus. "Disse então o homem: "Esta, sim, é osso dos meus ossos e carne da minha carne! Ela será chamada

\footnotetext{
${ }^{6}$ Veja, por exemplo, Lv 18.6-18; 23-28; Dt 22.22-30.
} 
mulher, por que do homem foi tirada". Mesmo tendo sido este casal criado diretamente por Deus, e, portanto, não tendo uma casa ou família para deixar, o Criador estabelece aqui o padrão a ser seguido pela sua Criação a partir deste ponto. Por essa razão, o homem deixará pai e mãe e se unirá à sua mulher, e eles se tornarão uma só carne" $(\mathrm{Gn} 2.23,24)^{7}$. Note-se a sequência dos fatos: ambos sairiam da casa de seus pais - indicando a independência do novo adulto; seguido da união - algo similar a uma cerimônia de casamento atual, para então tornarem-se uma só carne - a consumação do sexo. Note-se que esta instituição é estabelecida antes da queda (Gn 3), portanto tomou forma em ambiente moralmente puro, isento de pecado. A observação dos fatos subsequentes, a começar pela introdução do pecado, aponta para a deturpação da intenção inicial de Deus com Sua criação. A alegria, a naturalidade e as boas consequências desta prática, como a nudez sem vergonha (Gn 2.25) e a fertilidade que encheria a Terra (Gn 1.28), perderam parte de seu propósito graças ao pecado. A alegria do sexo e da sexualidade foi diretamente afetada pela disposição do Homem em seguir seus próprios caminhos.

Hollinger destaca que a criação divina relatada nos primeiros capítulos de Gênesis tem em seu contexto mais do que simplesmente a sequência dos fatos. Ele afirma que, "Se há um Deus que criou o mundo com significado e propósito, e sexualidade e sexo são parte deste mundo criado, então fica claro que há significado e propósito para esta dimensão da existência humana" (HOLLINGER, 2008, p. 70). Ou seja, mesmo que não haja menção direta ao tema em questão, este trecho bíblico deve ser considerado como fundamental para o entendimento divino sobre o ensino e a prática do sexo. ${ }^{8}$

As passagens do Novo Testamento parecem, à primeira vista, mais claras e diretas sobre o tema da castidade para seu povo. Há várias que condenam 'imoralidade sexual' ou ‘fornicação' - conforme a tradução escolhida. Porém a palavra grega utilizada é 'porneia' e segundo o Dicionário Bíblico New American Standard Hebrew-Aramaic and Greek Dictionaries: Updated Edition, esta expressão é genérica, indicando relações sexuais ilícitas, podendo incluir muitos comportamentos diferentes (1998). O critério entre relações lícitas e ilícitas, por outro lado, não está claro no texto, e precisa de maior atenção. Não está evidente no texto que o sexo antes do casamento é considerado ilícito. De acordo com Pelt, quatro

\footnotetext{
${ }^{7}$ Conforme Nova Versão Internacional, utilizada nesta e demais citações bíblicas deste texto - exceto quando indicado em contrário.

${ }^{8} \mathrm{O}$ Antigo Testamento ainda contem diversas referências à sexualidade e ao sexo. Destaca-se o livro de Cantares, por exemplo, apresenta a intimidade de um casal de maneira surpreendente quando comparado ao contexto bíblico. Este livro e as demais referências não foram tratados aqui por falta de espaço, e também por que contribuiriam menos para a construção da ideia da castidade até o casamento que se pretende desenvolver.
} 
significados claros podem ser tirados a partir das quarenta e sete vezes em que o termo 'porneia' é usado no Novo Testamento: adultério, imoralidade em geral, prostituição e casamento como um estado para se evitar porneia. O apóstolo Paulo usa o termo como um evidente estado de pecado: o seguidor de Cristo não deve se envolver em tal atividade e aqueles que estão devem se arrepender e mudar seu comportamento imediatamente (PELT, 1975, p. 601).

A Igreja tem se apropriado destas interpretações um tanto vagas, fazendo-as parecer com mandamentos claros que proíbem o sexo pré-marital. Porém a pregação deste mandamento, por si só, seja na história da Igreja ou na prática contemporânea parece não estar atingindo os resultados esperados. Limitar a relação sexual a um casal oficialmente casado por uma autoridade eclesiástica tem repelido muitos a qualquer compromisso com a religião cristã e consequentemente com o Criador. É tempo, portanto, que a Igreja observe a realidade ao seu redor e firme sua posição sobre este tema.

O correto entendimento sobre sexo e sua prática dentro deste conceito terão significativo impacto na vida do indivíduo. Hollinger define assim sua relevância:

A intimidade sexual é uma expressão e um nutriente do amor. Através do ato conjugal crescemos em intimidade com o outro, não apenas fisicamente, mas também emocionalmente e espiritualmente. Isto acontece porque o sexo é movido em sua essência pelo amor. A manhã seguinte aos momentos em que um casal desfrutou de seus corpos e almas, os indivíduos sentem-se renovados em seu compromisso mútuo. Fica até mais difícil discutir após a intimidade física, visto que houve uma entrega mútua total, e em contrapartida um receber integral daquilo que o parceiro entregou. Caso o sexo esteja vazio de tal amor, será luxúria egocêntrica, talvez até beirando o estupro, ao usar-se da outra pessoa para o prazer próprio (HOLLINGER, 2008, pp. 110$111)^{9}$.

O que se observa então é que para que a prática do sexo alcance seu significado e propósito, conforme intenção inicial e soberana do Criador, a mesma deve estar limitada ao casal oficialmente comprometido e debaixo do compromisso da exclusividade.

Tendo dito isso, a questão permanece: existe uma maneira melhor para a Igreja orientar a sexualidade de seus membros? Visto que cada vez menos seguidores da fé cristã seguem à orientação de se abster do sexo até o casamento, deve-se então procurar outro paradigma? ${ }^{10} E ́$ inegável que a 'Lei' tem sido ineficaz em muitos casos. no entanto ela será defendida. Porém,

\footnotetext{
${ }^{9}$ Hollinger destaca em seguida que esta não é a regra para toda relação sexual monogâmica. Há aquelas que, mesmo limitadas ao casal oficialmente casado, não são assim prazerosas e em alguns casos até mesmo violentas. Estas situações não serão abordadas aqui em função da limitação do artigo e seu objetivo central.

${ }^{10}$ Não foram encontradas estatísticas confiáveis sobre o comportamento sexual do evangélico brasileiro. Porém pode-se inferir que não seja muito diferente do norte-americano, dadas as semelhanças entre as culturas e a influência desta na teologia e comportamento daquela. Hollinger cita pesquisa realizada pela General Social Survey, em 2002, que aponta que $69 \%$ dos evangélicos norte-americanos solteiros pesquisados haviam praticado sexo nos últimos 12 meses.
} 
a argumentação não pode se estabelecer no texto bíblico somente, mas deve ser reforçada pela prática dos seus membros e na tradição da Igreja. Como mencionado anteriormente, defender a castidade até o dia do casamento exclusivamente pelo texto bíblico não interpretado parece difícil. Mas ainda assim, este deve ser o fundamento inicial e elementar da argumentação.

O que se procura aqui pode ser descrito como a moralidade do sexo. Nestes termos, Cahill afirma:

\begin{abstract}
A contribuição bíblica mais importante para a ética cristã da atividade sexual e de relacionamento entre os sexos é a colocação da moralidade na vida da comunidade de fé. A moralidade não é um interesse para sua própria causa, mas por causa da compreensão de como o povo de Deus vai viver e agir em relação ao próximo e para com o próximo no caso de se manterem fiéis. (CAHILL, 1985, p. 24).
\end{abstract}

Em outras palavras, a aplicação direta e literal de certas leis e ordenanças da Bíblia não é o suficiente para delinear práticas cristãs saudáveis sobre sexo e sexualidade. A moralidade da lei e características de Deus, como hospitalidade, amor, paz e justiça têm que desempenhar um papel no processo e cabe à comunidade fazer esta tradução. Também deve ser levado em consideração que a ética cristã vai muito além do interesse pessoal, do prazer individual. Esta ética levará sempre em consideração também o bem estar do próximo e da comunidade em que está inserido.

\title{
4 O CAMINHO A SEGUIR: SEXO (IN)FORMA A IGREJA
}

A comunidade de fé é responsável por formar e informar seus membros sobre práticas sexuais e conhecimentos a respeito. A Igreja é chamada a informar seus membros sobre a perspectiva cristã sobre sexualidade e criar maneiras em que isto é possível. Por outro lado, é a sexualidade das pessoas que forma, em parte, a Igreja. Se a ética cristã é baseada em contextos específicos e esta reside nas narrativas e na cosmovisão daqueles que fazem parte da comunidade, um dos grandes desafios da Igreja é permanecer relevante para a vida de seus membros e se manter atualizada em termos de comportamento social. Desde a discussão sobre a circuncisão e o dilema entre judeus e gentios até o advento da internet na era pós-moderna, a Igreja é chamada a reagir às mudanças sociais, o que exige uma nova interpretação das suas regras e práticas antigas. Em Atos 15, Lucas declara que houve “muito debate”. E Pedro afirma então categoricamente que a circuncisão é um jugo desnecessário e, portanto, não mais necessário sob a perspectiva da salvação através da graça em Jesus Cristo.

De maneira alguma isto significa que as instruções contidas na Bíblia têm data de validade ou então que tem suas orientações limitadas aos primeiros leitores das cartas ou 
escritos. O que se pretende demonstrar é que as mudanças de contexto, que acontecem em ritmo cada vez mais veloz, não podem ser ignoradas. Na medida em que se observa novas circunstâncias e práticas sociais, o mesmo texto bíblico deve ser novamente estudado e aplicado de forma coerente e contextualizado, sob pena de se tornar obsoleto e não respeitado, no caso de não observância deste processo. Caso contrário, o mandamento 'Não praticarás sexo antes do casamento!" continuará a fazer parte das leis ignoradas pelos cristãos.

Este estudo e debate pode, ou até deve em alguns casos, defender o seguimento das instruções de maneira literal, por mais que na grande maioria dos casos isto demande um exercício de aplicação prática. A atitude dos apóstolos, em conjunto com a Igreja Primitiva, em discutir algo que parecia absolutamente claro no texto canônico, mas não mais compatível com a Nova Aliança deve servir de inspiração para sua prática. O livro de Atos, mais do que um texto prescritivo sobre o comportamento do cristão e a Igreja de Cristo, tem conotação descritiva: como uma Igreja saudável, porém, até certo ponto imatura age em casos de divergência de opiniões.

Em outro contexto, mas seguindo o mesmo raciocínio, Cahill afirma que, "Como os textos sobre divórcio no Novo Testamento nos mostram, o processo de adaptação começa já dentro do cânon" (CAHILL, 1985, p. 24). A Igreja tem sido chamada de corpo, e uma das características desta imagem é a necessidade e a capacidade de se adaptar. O argumento de Cahill sobre divórcio mostra a necessidade de adaptação dentro do cânon, mas continua a ter o texto bíblico como o ponto de partida. $\mathrm{O}$ argumento aqui não tem a intenção de alterar a regra da Igreja sobre o sexo antes do casamento, mas sim de justificar e atualizar a mesma. O sexo deve ser praticado exclusivamente entre pessoas casadas, em cerimônia oficiada por um líder eclesiástico ordenado pela Igreja. E isto não somente pelo conteúdo do texto bíblico, mas também pela prática observada por essa mesma Igreja ao longo dos séculos. Se esperar até depois da cerimônia do casamento não garante uma vida sexual saudável, um comportamento mais liberal não o tornaria melhor. As dificuldades experimentadas pelos casais devem ser igualmente foco de atenção da Igreja, em ações intencionais de informação e discipulado.

No livro Premarital Guidance, Taylor cita uma pesquisa sociológica de Andrew Greeley sobre práticas religiosas e felicidade conjugal. Ele afirma,

[Greeley] descobriu que a alta satisfação conjugal e alta satisfação sexual forma mais frequentemente ligadas a orar diariamente, frequentar cultos semanalmente, e mantendo imagens positivas de Deus. Ele também descobriu que essas imagens positivas de Deus foram aprofundadas por ouvir sermões que enfatizavam o amor de Deus, participar de retiros de oração, e fazer a leitura devocional. Curiosamente, ambos os parceiros que oravam diariamente (isoladamente ou em conjunto) tiveram 
uma maior incidência de alta satisfação conjugal e alta satisfação sexual do que qualquer outro grupo nesta pesquisa. (TAYLOR, 1999, p. 9)

Embora não seja exatamente a prova da eficácia do aconselhamento pré-nupcial, a pesquisa de Greeley aponta para o fato de que as práticas cristãs são relevantes para o sucesso e felicidade do casamento. A avaliação e orientação de um casal nestas e outras chamadas 'práticas religiosas' durante o processo de preparação para o casamento devem enfatizar o valor das mesmas e encorajar o casal a continuar a praticá-las depois. Além disso, as práticas sugeridas por Greeley serão utilizadas mais adiante como sugestões para práticas que ajudam a moldar a sexualidade de um casal e, como consequência, podem moldar também a sociedade da qual fazem parte.

\section{COMO A IGREJA TEM CONTRIBUÍDO PARA A (DE)FORMAÇÃO SEXUAL DE SEUS MEMBROS}

Sendo constituída de pessoas, a Igreja comete falhas. Não é difícil constatar que a formação sexual de seus membros não é exceção a essa regra. A Igreja tem falhado, em grande parte, em proporcionar um ambiente saudável quando se trata de sexo e sexualidade. Recusando-se a falar sobre o assunto e a tomar decisões enérgicas quando tragédias acontecem nesta área, mais especificamente quando envolvem líderes, a Igreja tem, muitas vezes, dado mau exemplo. Krabill começa seu capítulo sobre o assunto desta forma:

\footnotetext{
[Greeley] está claro que muitas pessoas não estão dispostas a seguir as instruções divinas em seu viver diário. Entre as maiores preocupações das pessoas em nossas igrejas e na sociedade em geral está a consciência perturbadora de que alguma coisa está errada a respeito do amor, sexo, casamento e compromisso. Em muito à nossa volta vemos escombros e as vítimas da distorção da nossa sexualidade (KRABILL, 2010, p. 149).
}

Reconhecendo a influência de uma sociedade obcecada com a sexualidade unidimensional, ou seja, sexo, Krabill recorda o apóstolo Paulo, que adverte sobre a influência moral da sociedade sobre a ética cristã: "Rogo-lhes... que se ofereçam em sacrifício vivo... Não se amoldem ao padrão deste mundo, mas transformem-se pela renovação da vossa mente" (KRABILL, 2010, p. 149). O apelo consumista, a busca pela gratificação instantânea e o individualismo são apenas alguns exemplos de comportamentos seculares contemporâneos que estão moldando cristãos conformados em muitas áreas, incluindo a sexualidade.

De acordo com Hollinger, somos uma sociedade sexualmente confusa. Ele afirma: 
A mesma cultura que busca o sexo para suportar o dia-a-dia procura estabelecer limites que frequentemente parecem incongruentes a uma pessoa bombardeada o dia todo com imagens sexuais a alusões ao sexo... Em meio a tudo isso, somos uma cultura confusa no que tange a limites, e certos e errados da intimidade sexual (HOLLINGER, 2008, p. 11).

A confusão permeia a Igreja. Os líderes da Igreja muitas vezes têm a tendência de silenciar e evitar estes temas, enquanto o mundo secular sobrecarrega os cristãos com todos os tipos de ideias sobre sexo e sexualidade. Gushee critica a Igreja em silêncio quando o assunto é casamento:

A abordagem mais comum para o colapso de casamentos em igrejas hoje é o silêncio desconfortável. Quando confrontado com o divórcio, muitos ministros e pessoas da igreja caem em um estado de paralisia muda (GUSHEE, 2004, p. 187).

Pode parecer que estas palavras não estejam ligadas diretamente à questão do sexo e da sexualidade, mas as razões que Gushee cita para o silêncio podem apontar para uma semelhança entre os dois contextos.

A primeira razão é a sensibilidade pastoral, que deixa o ministro com medo de ofender ou magoar seus fiéis. Isto se intensifica com a distância, por vezes abissal, entre o que está sendo praticado pela maioria e aquilo que o ministro entende como sendo a melhor prática cristã. Outra possível razão para o silêncio é o risco de lembrar os fiéis de suas experiências dolorosas. A sexualidade é uma das mais profundas áreas emocionais da vida humana, e as dores causadas pela má conduta sexual, seja da própria pessoa ou de outra que a afete diretamente, estão entre as mais profundas experimentadas pela alma humana. O simples fato de mencionar alguns deles podem causar profundo desconforto entre eventuais vítimas, o que poderia acabar incentivando o pregador a procurar outro tema para o sermão do próximo domingo.

Mas não é somente no púlpito que se observa o silêncio sobre o tema também em interações individuais este é frequentemente evitado. Gushee afirma,

Considere a situação hipotética de um líder leigo da igreja que se envolve em um caso extraconjugal e planeja deixar esposa e família. A maioria das igrejas não tem uma cultura, práticas costumeiras, ou mesmo princípios constitucionais que autorizam alguém a desafiar o comportamento de um membro que está em clara violação do ensinamento bíblico. A falta de qualquer estrutura de prestação de contas deixa o silêncio desconfortável (e um monte de fofocas) como a resposta padrão para faltas graves na Igreja. (GUSHEE, 2004, p. 187) 
A falta de resposta pode envergonhar a comunidade cristã, e os problemas não abordados não são diminuídos por isso - muito pelo contrário. A resposta de Gushee é intencionalidade. A Igreja tem de ser intencional para orientar os membros a práticas saudáveis. Seja em casos de divórcio ou questões ligadas a sexo e sexualidade, a Igreja precisa tomar posição. Deixando as coisas como estão certamente não melhorará os resultados. Como em vários outros temas, também neste a Igreja é chamada a ser contra cultural, em obediência às palavras já citadas do apóstolo Paulo aos Romanos. Mas algo estranho acontece quando se trata de sexualidade: a mídia secular sobrecarrega a sociedade com sexo, enquanto a Igreja está em silêncio. A interpretação correta do trecho da carta aos Romanos parece apontar ao não-silêncio. A oposição ao bombardeio da mídia precisa de voz, de volume, de argumentos e ações. A resposta contra cultural deve falar a respeito, porém em outros termos.

\section{CONCLUSÃO}

É tempo de os cristãos, e consequentemente a Igreja, apropriarem-se de um dos grandes presentes dados por Deus àqueles feitos à sua imagem e semelhança. $\mathrm{O}$ tema da sexualidade e sua prática não podem mais ficar limitados ao tratamento corretivo de casos onde a mesma foi desvirtuada. Da mesma forma, não é mais suficiente - de fato nunca foi - apenas conformar-se com a mensagem aos não casados de que não devem praticar sexo, e após o casamento supor que tudo estará bem entre o casal.

Conforme apresentado acima, a questão não se resolve com 'sim' ou 'não'. Não basta ao cristão saber e procurar se ater à orientação de quando o sexo é proibido e quando não. A Bíblia tem muito mais informações a respeito, mas precisa ser lida, com coragem e atenção, para que um tema de tamanha relevância na vida do cristão seja entendido e praticado de maneira a trazer todo o prazer e satisfação disponíveis em lugar do medo e da culpa. O texto bíblico foi sim escrito em contextos bastante distintos do atual, e isto torna esta descoberta mais desafiadora.

O texto de Gênesis, mencionado acima, é talvez o mais apropriado e completo para a fundamentação da defesa da tese da castidade até o casamento. $\mathrm{O}$ entendimento da Criação como perfeita, e também como referencial para vida e comportamento do cristão, deixa bem menos dúvidas do que a expressão 'porneia' de Paulo. Não que esta deva ser ignorada ou deixada em segundo plano, mas que somente serve de referencial se colocada sob a luz do significado e propósito inicial do Criador para este tema. 
Uma vez aceito o desafio do estudo da Bíblia e sua autoridade para nortear o comportamento do cristão, vem a parte ainda mais desafiadora: informar o cristão e formar sua conduta sobre este tema. O silêncio praticado no que tange a este aspecto da vida tornará este passo constrangedor, embaraçoso. A igreja precisa de cautela, mas ao mesmo tempo de coragem e de sinceridade para iniciar o processo. Como dito no início do texto, a sexualidade está presente em todas as fases do desenvolvimento humano, então poder-se-ia iniciar a educação sobre este tema entre as crianças. Sendo feito em consonância com seus pais, a educação sexual infantil prepararia esta geração para a sobrecarga que estão prestes a receber ao ingressarem no mundo da adolescência. Teria também um efeito colateral positivo, de provocar esta conversa nas famílias, onde poderia deixar de ser tabu.

Para que as demais gerações sejam ensinadas, uma dose um pouco maior de coragem e criatividade seria necessária. Mas não parece intangível que adolescentes tenham momentos de conversas informais, porém formativas sobre este tema com adultos, em grupos ou individualmente. Da mesma forma, jovens e adultos deveriam ter contato com o tema, desde eventos específicos para casais até o chamado 'sermão de domingo' - momento clássico de ensino e pregação semanal nos encontros de adoração da Igreja.

Tendo sido criados como seres sexuais, onde desejos e práticas podem ser experiências positivas, e por que não dizer prazerosas e até mesmo formativas para o ser humano e a sociedade, a Igreja Contemporânea tem a responsabilidade de aprender e ensinar a respeito. $\mathrm{O}$ que se convencionou chamar de 'mundo' está fazendo isso - moldando o comportamento e vencendo a batalha dos argumentos tendo a seu favor a grande intensidade com que aborda o assunto. Se os argumentos não podem ser vencidos pela frequência, que sejam então pela veracidade e pureza de intenções, sabendo que as instruções da Bíblia são atuais e apontam para a vida abundante de seus seguidores e praticantes. 


\section{REFERÊNCIAS}

AGOSTINHO. Confissões ( $2^{\mathrm{a}}$ ed.). São Paulo: Vozes, 2011.

CAHILL, L. S. Between the Sexes: Foundations for a Christian Ethics of Sexuality. Minneapolis, MN: Fortress Press, 1985.

diversos autores. Hebrew-Aramaic Dictionary of the New American Standard Exhaustive Concordance. La Habra, CA: The Lockman Foundation, 1998.

DUARTE, C. Vamos falar daquilo? Rio de Janeiro: Coisas de crente, 2014.

GUSHEE, D. P. Getting Marriage Right: Realistic Counsel for Saving and Strengthening Relationships. Grand Rapids, MI: Baker Books, 2004.

HOLLINGER, D. P. The Meaning of Sex. Grand Rapids, MI: Baker Academic, 2008.

http://michaelis.uol.com.br. Acesso em 30 de Novembro de 2016, disponível em michaelis.uol.com.br: http://michaelis.uol.com.br

https://dicionariodoaurelio.com. Acesso em 30 de Novembro de 2016, disponível em Dicionário do Aurélio: https://dicionariodoaurelio.com

KRABILL, A. Sexuality: God's Gift. Scottdale, PA: Herald Press, 2010.

PELT, M. V. The Zondervan Pictorial Encyclopedia of the Bible. Grand Rapids, MI: Zondervan Pub. House, 1975.

SILVA, M. C. Sexualidade Começa na Infância. São Paulo: Casa do Psicólogo, 2007.

TAYLOR, C. W. Premarital Guidance. Minneapolis: Fortress Press, 1999.

WINNER, L. Real Sex. Grand Rapids, MI: Brazos, 2005.

www.aimb.org.br/nossa-fe. Acesso em 22 de 08 de 2016, disponível em www.aimb.org.br/nossa-fe 